\title{
"Tão nova e com os peitinhos caídos": analisando o governo dos corpos femininos no Instagram
}

\author{
"Tan nueva y con los pechos caídos": analizando el gobierno de los \\ cuerpos femeninos en el Instagram
}

\section{"So young and with the little tits fallen": analyzing the government of the female bodies in Instagram}

\author{
Débora Cristina Dias Pinto ${ }^{1}$ \\ Taina Guerra Chimieski ${ }^{2}$ \\ Raquel Pereira Quadrado3
}

\begin{abstract}
Resumo
O presente artigo consiste na análise da rede de enunciações que se produziu a partir de uma foto postada pela atriz brasileira Bruna Marquezine no site da rede social Instagram, referente à sua participação no bloco de carnaval "A Favorita", no Rio de Janeiro. Entendemos que, na atualidade, os sites de redes sociais se constituíram em um potente espaço de diálogo e também de propagação de discursos tidos como "verdadeiros" acerca dos mais diversos temas, dentre eles os corpos. Na foto em questão, a mesma usava short e sutiã de pedrarias que cobria parcialmente os seios, motivo pelo qual recebeu inúmeras críticas de seguidores de seu perfil, assim como tantos outros comentários de apoio à exibição do corpo natural. A postagem foi realizada em fevereiro de 2018, e tem mais de 2 milhões de curtidas e 100 mil comentários. A partir dessa repercussão, acreditamos ser importante a discussão acerca do governo dos corpos femininos, amplamente difundido na sociedade contemporânea, especialmente nos espaços virtuais. Para análise, utilizamos os pressupostos dos Estudos Culturais.
\end{abstract}

Palavras-Chave: Espaços virtuais; Estudos Culturais; Governo dos corpos femininos.

\section{Resumen}

El presente artículo consiste en el análisis de la red de enunciaciones que se produjo a partir de una foto publicada por la actriz brasileña Bruna Marquezine en el sitio de la red social Instagram, referente a su participación en el bloque de carnaval "A Favorita", en Río de Janeiro. Entendemos que, en la actualidad, los sitios de redes sociales se constituyeron en un potente espacio de diálogo y también de propagación de discursos tenidos como "verdaderos" acerca de los más diversos temas, entre ellos los cuerpos. En la foto en cuestión, la misma usaba short y sujetador de pedrerías que cubría parcialmente los senos, por lo que recibió innumerables críticas de seguidores de su perfil, así como tantos otros comentarios de apoyo a la exhibición del cuerpo natural. La entrada se realizó en febrero de 2018, y tiene más de 2 millones de curtidos y 100 mil comentarios. A partir de esa repercusión, creemos que es importante la discusión acerca del gobierno de los cuerpos femeninos, ampliamente difundido en la sociedad contemporánea, especialmente en los espacios virtuales. Para el análisis, utilizamos los presupuestos de los Estudios Culturales.

Palabras claves: Espacios virtuales; Estudios Culturales; Gobierno de los cuerpos femeninos.

1 Mestranda no Programa de Pós-Graduação em Educação em Ciências: Química da Vida e Saúde; Universidade Federal do Rio Grande - FURG; Rio Grande, Rio Grande do Sul, Brasil; debora_diasp@hotmail.com.

2 Doutoranda no Programa de Pós-Graduação em Educação em Ciências: Química da Vida e Saúde; Universidade Federal do Rio Grande - FURG; Rio Grande, Rio Grande do Sul, Brasil; taina.bio@hotmail.com.

3 Doutora em Educação em Ciências; Universidade Federal do Rio Grande - FURG; Rio Grande, Rio Grande do Sul, Brasil; raquelquadrado@hotmail.com. 


\begin{abstract}
The present article consists of the analysis of the network of enunciations that was produced from a photo posted by Brazilian actress Bruna Marquezine on the social network website Instagram, referring to her participation in the carnival block "A Favorita" in Rio de Janeiro. We understand that, in the present day, social networking sites have become a powerful space for dialogue and also the propagation of discourses considered as "true" about the most diverse themes, among them the bodies. In the photo in question, she wore shorts and bra of shiny stones that partially covered the breasts, reason for which received innumerable critics of followers of its profile, as well as many other comments in support to the exhibition of the natural body. The post was held in February 2018, and has more than 2 million tanned and 100 thousand comments. From this repercussion, we believe to be important the discussion about the government of the female bodies, widely diffused in the contemporary society, especially in the virtual spaces. For analysis, we used the assumptions of Cultural Studies.
\end{abstract}

Keywords: Cultural Studies; Government of women's bodies; Virtual spaces.

\title{
1. Introdução
}

Há décadas o corpo está em voga, porém, nos dias atuais, os discursos e os modelos de corpos tidos como perfeitos, giram em torno de três vetores: beleza, vigor e juventude (COUTO, 2004). No intuito de melhorá-lo, torná-lo mais atrativo, jovem e desejável, não se medem esforços. "Para o homem ocidental, o corpo se tornou o lugar da sua identidade seu modo de ser. [...] A todo instante somos convidados/as a administrar a própria aparência, a superar e redesenhar formas físicas” (COUTO, 2004, p. 119). Ou, como afirma Tucherman (2009, p. 15), “o que se experimenta hoje não é ser um corpo, mas ter um corpo que sempre podemos, se não recusar totalmente, aprimorar, seja em relação à aparência que desejamos ter, seja em relação à potencialização das funções que merecem nosso interesse".

Ancorado na perspectiva teórica dos Estudos Culturais, em sua vertente pósestruturalista, este artigo visa analisar a rede de enunciações que se produziu, a partir dos comentários realizados em uma postagem da atriz brasileira Bruna Marquezine, no site da rede social Instagram. A publicação foi realizada em 10 fevereiro de 2018, e refere-se a sua participação no bloco de carnaval "A Favorita", do Rio de Janeiro. Na postagem havia duas fotos da atriz que vestia short e sutiã de pedrarias, recebendo inúmeras críticas de seguidores do seu perfil - especialmente em relação aos seios -, assim como tantos outros elogios pela exibição do que eles chamaram de "corpo natural". 

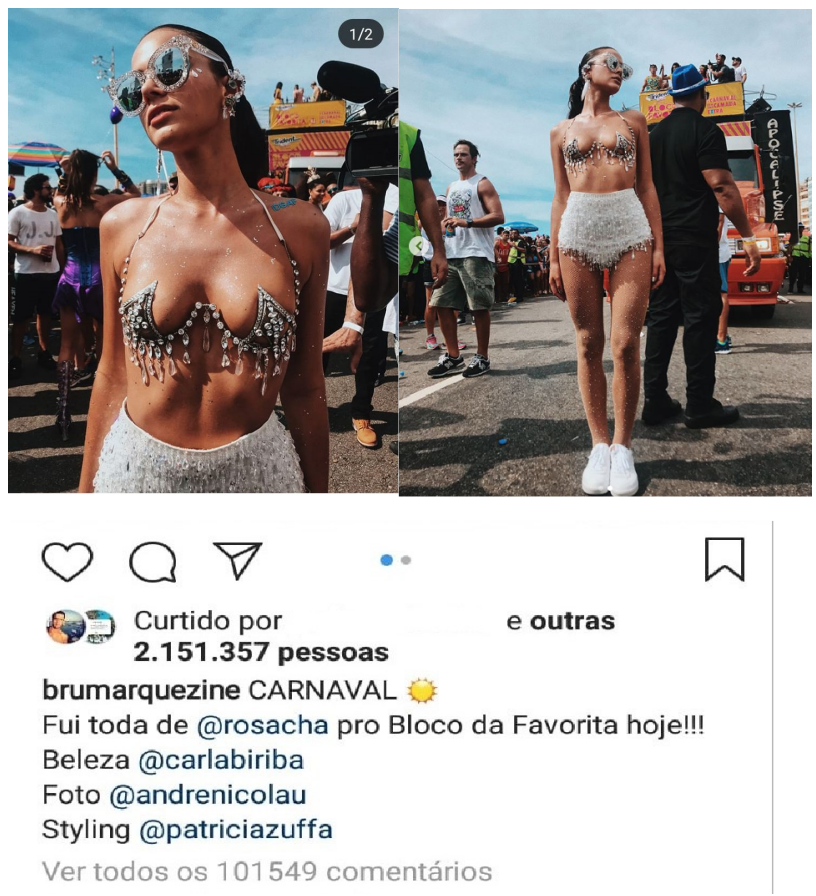

Figura 1 - Postagem da atriz Bruna Marquezine no Instagram

Fonte: https://www.instagram.com/p/BfB0EUxli z/?hl=pt-br. Acesso em 05 de novembro de 2018.

A postagem recebeu mais de dois milhões de curtidas e mais de cem mil comentários. Diante dessa repercussão, julgamos ser importante a discussão acerca do governo dos corpos femininos, tão amplamente difundido na sociedade contemporânea, especialmente nos espaços virtuais.

Para este artigo, utilizamos alguns pressupostos da análise cultural, da mesma forma que, optamos por analisar apenas os comentários que faziam críticas à atriz, no intuito de entender que rede de enunciações foi produzida a partir da postagem.

\section{Referencial Teórico}

Ao longo dos anos, múltiplos discursos sobre o corpo emergiram com os mais variados objetivos, dentre os quais podemos citar: descrever, analisar, categorizar, atribuir sentido, estabelecer normas, demarcar, instituir lugares. Logo, há muito tempo o corpo tem sido objeto de estudo, entendendo que para melhor controlá-lo era necessário primeiro conhecer seu funcionamento.

A partir de Foucault (2004, p. 22), compreendemos o corpo como "superfície de inscrição dos acontecimentos (enquanto que a linguagem os marca e as ideias os dissolvem), lugar de dissociação do Eu (que supõe a quimera de uma unidade substancial), volume em perpétua pulverização". Desta forma, destacamos que não existe apenas um corpo, mas sim 
corpos - múltiplos e distintos -, que não são apenas a materialidade biológica que os constitui. Pensar os corpos nessa perspectiva nos permite entender que eles estão em constante processo de reinvenção e ressignificação, constituindo-se como construções, fabricações.

Deste modo, os corpos são produções biossociais, ou seja, eles são produzidos a partir do entrelaçamento entre a materialidade biológica e os inúmeros discursos e narrativas que os interpelam, como aponta Silvana Goellner:

[...] mais do que um dado natural cuja materialidade nos presentifica no mundo, o corpo é uma construção sobre a qual são conferidas diferentes marcas em diferentes tempos, espaços, conjunturas econômicas, grupos sociais, étnicos, etc. Não é, portanto, algo dado a priori nem mesmo é universal: o corpo é provisório, mutável e mutante, suscetível a inúmeras intervenções consoante o desenvolvimento científico e tecnológico de cada cultura bem como suas leis, seus códigos morais, as representações que cria sobre os corpos, os discursos que sobre ele produz e reproduz (2013, p. 30).

Compreender os corpos como construções biossociais não implica em negar a materialidade biológica, mas sim, entender que ela não é o único fator que os constitui. Os corpos são produzidos e modificados a partir da interação entre a sua anatomia, a cultura e os múltiplos discursos que os interpelam. Os corpos fazem sentido dentro de redes de significações culturais, históricas e sociais, carregam as marcas de sua época, suas crenças, sua posição social.

Os corpos foram e ainda são, alvos do poder. De acordo com Michel Foucault (2013, p. 131), o poder disciplinar atua sobre o corpo do indivíduo, buscando torná-lo disciplinado, dócil e útil, "tudo isso assegurado por procedimentos de poder que caracterizam as disciplinas anátomopolíticas do corpo humano".

Para Foucault (2013), além do poder disciplinar, que tem como foco o corpo do indivíduo, temos também o biopoder, que foca em gerir o corpo social - a população -, e para tal, apoia-se em saberes e práticas que gerem taxas de natalidade, aumento da longevidade, epidemias, etc. O biopoder se exerce através de estratégias biopolíticas, que visam à regulamentação da população, buscando prever seus eventos, "controlar (eventualmente modificar) a probabilidade desses eventos, em todo caso, compensar seus efeitos" (FOUCAULT, 2002, p. 297). Desta forma, o biopoder tem por finalidade fazer viver e apoiase na medicina "para aumentar a vida, para controlar seus acidentes, suas eventualidades, suas deficiências" (id., p. 295).

No intuito de fazer viver o corpo social, o corpo da mulher torna-se alvo de regulação e controle, tendo em vista sua função reprodutiva. Dessa forma, o corpo feminino, por apresentar um importante papel social e político, é submetido à vigilância, disciplina e 
controle. Esse governo dos corpos não ocorre de maneira uniforme, ou seja, não se exerce da mesma maneira sobre todos os indivíduos; por isso, existe a necessidade de uma atuação contínua através de diferentes instâncias e aparatos sociais (SANTOS, 2002).

Aqui, estamos entendendo governo para além das estruturas políticas do Estado, ou seja, a "maneira de dirigir a conduta dos indivíduos ou dos grupos" (DREYFUS; RABINOW, 1995, p. 244). Desse modo, o governo dos corpos e das condutas ocorre em meio a relações de poder, em que somos "governados" uns pelos outros, através de "mecanismos e procedimentos destinados a conduzir os homens, a dirigir a conduta dos homens, a conduzir a conduta dos homens" (FOUCAULT, 2009, p. 21). Por conseguinte, percebemos que múltiplas estratégias e discursos atuam na produção e governo dos corpos, especialmente os femininos, tendo em vista o papel que lhe é atribuído no corpo social.

Costa (2002) assinala, em seus estudos sobre mídia como pedagogia cultural, que as narrativas contidas nas mídias são manifestações culturais produtivas, pois permitem inventar identidades, regular, coordenar e governar. Logo, aquilo que é dito, é também inventado, fazendo com que o que nomeamos de realidade seja um misto de cultura e linguagem.

Nesse sentido, entendemos os discursos a partir de Foucault (2014, p. 60), “como práticas que formam sistematicamente os objetos de que falam". Assim sendo, os discursos são produzidos em imbricadas relações de saber/poder. Deste modo, quem profere o discurso e os lugares por onde ele circula, produzem efeitos de verdade, assumindo diferentes estatutos de legitimidade, a partir das relações de poder existentes. Isto ocorre "porque esses mecanismos de poder tornam possíveis, induzem essas produções de verdades, e porque essas produções de verdade têm efeitos de poder" (FOUCAULT, 2003, p. 229).

Consideramos que, na contemporaneidade, as mídias, em suas mais diferentes instâncias culturais (revistas, sites, propagandas, novelas, filmes,...), são espaços pedagógicos que atuam na produção dos sujeitos e suas subjetividades. Então, entendendo a mídia como uma instância educativa, apresentamos algumas análises referentes à postagem da atriz Bruna Marquezine no site da rede social Instagram.

\section{Resultados e Discussão}

Devido a grande repercussão e o número expressivo de comentários na postagem, optamos por analisar os últimos 500 comentários presentes na mesma. Estes foram agrupados por semelhança, de acordo com os eixos temáticos que mais se destacaram, embora, por vezes, alguns comentários se encaixassem em mais de um eixo. Destacamos os seguintes eixos encontrados nos comentários: críticas ao corpo, discurso moral/religioso e comparação 
com outras mulheres. Apresentamos a seguir cada eixo, com comentários representativos dos mesmos, além das problematizações.

\subsection{Críticas ao corpo}

$\mathrm{Na}$ época presente, "ostentamos o corpo sob o olhar vigilante do outro, como um acessório da moda que deve ser atualizado incessantemente" (PAIVA, 2009, p. 146). "É no corpo e através do corpo que os processos de afirmação ou transgressão das normas regulatórias se realizam e se expressam. Assim, os corpos são marcados social, simbólica e materialmente - pelo próprio sujeito e pelos outros" (LOURO, 2015, p. 85).

Dentro desse eixo temático, identificamos inúmeras críticas ao corpo da atriz, seja por considerarem que seus seios não estão dentro do padrão esperado para uma mulher jovem, seja por considerarem que a mesma está muito magra, embora esse seja o modelo corporal dito como "ideal" na nossa sociedade.

Cabe salientar que, os comentários que criticavam o corpo de Bruna, em sua maioria, partiram de mulheres, explicitando o quanto a cultura do machismo é enraizada também nas mulheres, e reproduzida no seu cotidiano.

Para Barboza (2013, p. 353), “é possível vislumbrar que o corpo feminino está submetido, mais que qualquer outro, não só às imposições de gênero, mas também a diversos instrumentos de "docilização", como os ditames do mercado de consumo", conforme nos mostra a Figura 2.

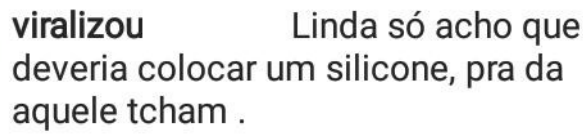

Figura 2 - Comentário publicado na postagem de Bruna Marquezine

Fonte: https://www.instagram.com/p/BfB0EUxli z/?hl=pt-br. Acesso em 05 de novembro de 2018.

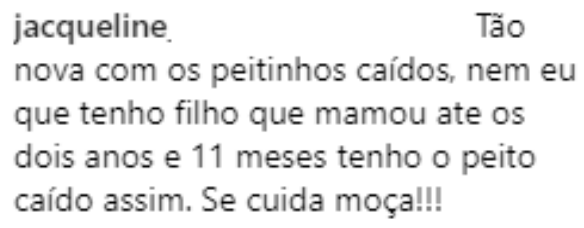

Figura 3 - Comentário publicado na postagem de Bruna Marquezine

Fonte: https://www.instagram.com/p/BfB0EUxli z/?hl=pt-br. Acesso em 05 de novembro de 2018. 
RELACult - Revista Latino-Americana de Estudos em Cultura e Sociedade

Revista Latinoamericana de Estudios en Cultura y Sociedad | Latin American Journal of Studies in Culture and Society IV EHM e III CLAEHM, ed. especial, mar., 1307, artigo $n^{\circ}$ XX | relacult.claec.org | e-ISSN: 2525-7870

mirian $\quad$ Bruna coitada Sta só
pele e osso

Figura 4 - Comentário publicado na postagem de Bruna Marquezine

Fonte: https://www.instagram.com/p/BfB0EUxli_z/?hl=pt-br. Acesso em 05 de novembro de 2018.

Os discursos, presentes nestas postagens, responsabilizam Bruna por seu corpo e sua aparência. Neles é apontado o problema, que consiste em ela ser jovem demais para ter determinado tipo de seio, e também lhe é concedida a solução, colocar um silicone. "O que é propagado no presente é que a beleza é construída, pode ser comprada, é fruto de um trabalho individual, cotidiano e responsável sobre o próprio corpo. Só é feio quem quer, quem se menospreza, não cuida adequadamente de si" (COUTO, 2004, p. 137). "A indústria do design corporal, os imperativos da aparência e da juventude, enfatizam que nada mais na anatomia é um destino. No corpo sem limites, tudo é escolha" (COUTO, 2012, p. 107).

Os discursos produzem uma "verdade" sobre os sujeitos e sobre seus corpos quando sugerem o que vestir, o que usar, o que falar, como se comportar, etc., constituindo identidades. Esta produção de identidades pelos discursos, ao mesmo tempo em que inspira liberdade, organiza práticas de disciplinamento e de controle. A transformação dos corpos na atualidade, prisioneiros do discurso da eterna juventude, transforma homens e mulheres em máscaras mal feitas de uma mesma formatação (COLLING, 2014, p. 37).

Nesse sentido, ao ditar como a atriz deve apresentar/expor seu corpo, o que é adequado ou não para a idade dela, a sociedade acaba por ditar e normalizar práticas de governo sobre os corpos femininos. Tais discursos contribuem para uma busca incessante e incansável pelo corpo dito perfeito, a partir dos padrões de beleza contemporâneos que mudam em uma velocidade estrondosa.

\subsection{Discurso moral/religioso}

Os discursos ancorados na moral e na religião possuem um caráter formador e orientador das condutas, especialmente em relação ao governo dos corpos femininos. Investimos muito nos corpos. "De acordo com as mais diversas imposições culturais, nós os construímos de modo a adequá-los aos critérios estéticos, higiênicos, morais, dos grupos a que pertencemos" (LOURO, 2000, p. 8). Logo, os comentários apresentados apontam que Bruna está expondo seu corpo em roupas que não são adequadas para o que a sociedade espera de uma mulher decente. 
RELACult - Revista Latino-Americana de Estudos em Cultura e Sociedade

Revista Latinoamericana de Estudios en Cultura y Sociedad | Latin American Journal of Studies in Culture and Society IV EHM e III CLAEHM, ed. especial, mar., 1307, artigo $n^{\circ} \mathrm{XX} \mid$ relacult.claec.org | e-ISSN: 2525-7870

bernadete Quê isso é carnaval ou
bordel

Figura 5 - Comentário publicado na postagem de Bruna Marquezine

Fonte: https://www.instagram.com/p/BfB0EUxli_z/?hl=pt-br. Acesso em 05 de novembro de 2018.

maycom A mais vulgar das
atrizes globais

Figura 6 - Comentário publicado na postagem de Bruna Marquezine

Fonte: https://www.instagram.com/p/BfB0EUxli_z/?hl=pt-br. Acesso em 05 de novembro de 2018.

isaac Depois fala que aceitou
Jesus

Figura 7 - Comentário publicado na postagem de Bruna Marquezine

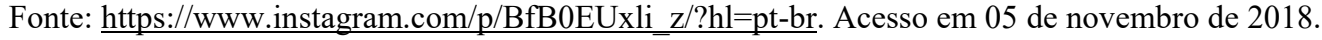

Silva e Ribeiro (2008) apontam que existe uma rede de estratégias que busca controlar e governar o corpo da mulher, disciplinando esse corpo e regulando a sua existência, o que pode ser confirmado nos comentários das Figuras 5, 6 e 7. Ao descrever a atriz como vulgar, e indagar se sua vestimenta era para o carnaval ou para um bordel, os usuários do site da rede social Instagram determinam que existe uma forma correta e adequada para as mulheres se vestirem.

Este padrão de comportamento e moral está ligado às origens do modelo de mulher presente no cristianismo, a Virgem Maria. Este reporta a mulher como submissa, frágil, tendo a maternidade como destino e à dessexualização do corpo feminino, características que devem ser valorizadas e buscadas pelas mulheres. Já no outro lado do espectro temos o modelo a ser negado e recusado por ser causador de todas as desgraças da humanidade - Eva -, que reporta à liberdade de escolha, à sexualidade com liberdade, à tomada de iniciativa, à curiosidade, à vontade de saber (BUSIN, 2011). Eva é retratada como a pecadora e desencaminhadora, por isso seu comportamento deve ser repelido e combatido. De acordo com Busin (2011, p. 118) "esses modelos são antagônicos e funcionam de forma importante para o controle dos corpos e da vida das mulheres". 
Os corpos considerados "normais" e "comuns" são, também, produzidos através de uma série de artefatos, acessórios, gestos e atitudes que uma sociedade arbitrariamente estabeleceu como adequados e legítimos. Nós também nos valemos de artifícios e de signos para nos apresentarmos, para dizer quem somos e dizer quem são os outros (LOURO, 2015, p. 89).

Desta maneira, de acordo com a autora, ao apontar a vulgaridade de Bruna, o usuário demonstra sua rejeição e aversão a tal comportamento, colocando-se em um lugar diferente, e de mais valia, do que o ocupado pela atriz. Desta forma, nos constituímos na diferenciação do outro. Nesse ínterim de comparação e diferenciação com o outro apresentamos o terceiro eixo de análise.

\subsection{Comparação com outras mulheres}

$\mathrm{Na}$ postagem realizada por Bruna, foram marcadas apenas as pessoas que, de alguma forma, estavam envolvidas com a sua produção para aquele evento (cabelo, maquiagem, roupa). Entretanto, alguns/algumas de seus/suas seguidores/as mencionaram outras mulheres famosas, comparando-as, e posicionando Bruna num lugar de inferioridade, como se, com a postagem, ela quisesse competir ou se parecer com determinada pessoa, como podemos observar abaixo:

$$
\begin{aligned}
& \text { michele Pra você chegar } \\
& \text { aos pés da Kim Kardashian tem que } \\
& \text { colocar seu peitos no lugar }
\end{aligned}
$$

Figura 8 - Comentário publicado na postagem de Bruna Marquezine

Fonte: https://www.instagram.com/p/BfB0EUxli z/?hl=pt-br. Acesso em 05 de novembro de 2018.

$$
\begin{aligned}
& \text { nielly Muito estranha } \\
& \text { parece que ta desnutrida so mostra } \\
& \text { osso ja foi bonita agora ta nuito feia a } \\
& \text { marina Ruy barbosa ganha dela }
\end{aligned}
$$

Figura 9 - Comentário publicado na postagem de Bruna Marquezine

Fonte: https://www.instagram.com/p/BfB0EUxli z/?hl=pt-br. Acesso em 05 de novembro de 2018.

Nesses comentários, podemos observar o que Lipovetsky (2000) chama de "febre da beleza-magreza-juventude", que exerce uma "tirania implacável sobre a condição das mulheres". Para o autor,

[...] a obsessão da magreza, a multiplicação dos regimes e das atividades de modelagem do corpo, os pedidos de redução de culotes e de modelagem até dos 
narizinhos arrebitados testemunham o poder normalizador dos modelos, um desejo maior de conformidade estética que se choca frontalmente com o ideal individualista e sua exigência de personalização dos sujeitos (LIPOVETSKY, 2000, p. 143).

Então, ao compararem o corpo de Bruna com o de outras mulheres, os/as seguidores/as apontam sua insatisfação com o fato da atriz não estar dentro dos padrões esperados e desejados para alguém de sua idade e reconhecimento social. Desta forma, ao mesmo tempo em que valorizamos o individual e o singular, paradoxalmente buscamos encaixar os demais na uniformidade, na conformidade dos padrões de beleza socialmente e culturalmente construídos.

Também houve comentários que comparavam os seios de Bruna aos seios da própria autora do comentário, porém, explicitando que esta última havia amamentado, o que justificaria ter os seios "caídos", diferentemente da Bruna que não tem filhos, conforme aparece na Figura 10.

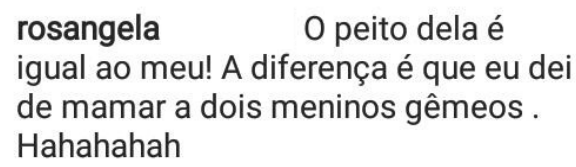

Figura 10 - Comentário publicado na postagem de Bruna Marquezine

Fonte: https://www.instagram.com/p/BfB0EUxli z/?hl=pt-br. Acesso em 05 de novembro de 2018.

O comentário acima expõe o relapso de Bruna com seu corpo, visto que, seu peito está caído de forma semelhante ao da seguidora que amamentou dois filhos. Nesse sentido, Souza et. al. (2013, p. 63) apontam que "a busca por padrões estéticos deixou de ser um dever social que pode ser conseguido ou não, e passou a ser um dever moral, para o qual a mulher deverá se esforçar o suficiente para conquistar”. Portanto, ser e estar bela passa a ser um dever, uma responsabilidade social da mulher.

Tais comentários contribuem para a manutenção dos discursos sobre o que é ser bela, o que é ser mulher, qual o comportamento e a vestimenta adequada para o feminino, entre outros. Discursos estes que atuam no gerenciamento e governo dos corpos femininos, tanto da Bruna, quanto das suas seguidoras e das demais mulheres.

\section{Considerações Finais}

A partir da problematização destes três eixos nos quais categorizamos os comentários, percebemos que os/as autores/as dos mesmos estão reproduzindo o discurso hegemônico do 
que é "ser mulher" na nossa sociedade, valendo-se de considerações ditas naturalizadas, como: a vaidade e os cuidados com o próprio corpo (que vão do peso corporal ao que deve ser "melhorado" através de procedimentos estéticos e cirúrgicos), o que se pode/deve vestir, como deve se portar, entre tantos outros.

Consideramos que existem múltiplas formas de ser mulher, como também existem múltiplos corpos, não sendo possível se pensar em um "modelo" ou "padrão" que deva ser adotado por todas. Esse tipo de pensamento é reflexo de uma cultura machista, ainda muito presente hoje, que coloca o feminino em posição de inferioridade ao masculino, e que está tão enraizada em nós, que acaba sendo reproduzida pelas próprias mulheres.

Destacamos ainda que, trazer à luz discussões que busquem a igualdade entre os gêneros é, neste momento, uma forma de resistência perante a onda de conservadorismo e retrocessos que vem se instaurando na nossa sociedade.

\section{Referências}

BARBOZA, Heloisa Helena. A docilização do corpo feminino. In: SILVA, Daniele Andrade da, et al. (Orgs.). Feminilidades: corpos e sexualidades em debate. Rio de Janeiro: EdUERJ, 2013, p. 351-362.

BUSIN, Valéria Melki. Religião, sexualidade e gênero. Revista de Estudos da Religião Rever, v. 11, n. 1, jan-jun/2011, p. 105-124. ISSN 1677-1222. Disponível em: https://revistas.pucsp.br/index.php/rever/article/view/6032. Acesso em: 08 jan. 2019.

COLling, Ana Maria. Tempos diferentes, discursos iguais: a construção do corpo feminino na história. Dourados: Ed. UFGD, 2014.

COSTA, Marisa Vorraber. Ensinando a dividir o mundo: as perversas lições de um programa de televisão. Revista Brasileira de Educação, Rio de Janeiro, v. 1, n. 20, p. 71-82, maioagosto/2002. ISSN 1413-2478. Disponível em: http://dx.doi.org/10.1590/S141324782002000200006. Acesso em: 09 nov. 2018.

COUTO, Edvaldo S. Corpos interditados: notas sobre anatomias depreciadas. In: STREY, Marlene Neves; CABEDA, Sonia T. Lisboa (Org.). Corpos e subjetividades em exercício interdisciplinar. Porto Alegre: EDUPUCRS, 2004, p. 133-148.

. Corpos voláteis, corpos perfeitos: estudos sobre estéticas, pedagogias e políticas do pós-humano. Salvador: Edufba, 2012.

DREYFUS, H. L; RABINOW, P. Michel Foucault: Uma trajetória filosófica: para além do estruturalismo e da hermenêutica. Tradução: Vera Porto Carrero. Rio de Janeiro: Forense Universitária, 1995.

FOUCAULT, Michel. Em defesa da sociedade: curso no Collége de France (1975-1976). Tradução: Maria Ermantina Galvão. São Paulo: Martins Fontes, 2002. 
Poder e saber. In: Manoel Barros da Motta (Org.). Ditos e escritos IV: Estratégia, poder-saber. Tradução: Vera Lucia Avellar Ribeiro. Rio de Janeiro: Forense Universitária, 2003, p. 223-240.

. Microfísica do poder. 28. ed. Rio de Janeiro: Paz e Terra, 2004.

. Do governo dos vivos: curso no Collége de France, 1979-1980: excertos. Rio de Janeiro: Achiamé, 2009.

. Vigiar e punir: História da violência nas prisões. 41.ed. Petrópolis, RJ: Vozes, 2013.

. Arqueologia do saber. 8.ed. Rio de Janeiro: Forense Universitária, 2014.

GOELLNER, Silvana. A produção cultural do Corpo. In: LOURO, Guacira L., et al. Corpo, gênero e sexualidade um debate contemporâneo na educação. 9. ed. Petrópolis: Vozes, 2013, p. $30-42$.

LIPOVETSKY, Gilles. A terceira mulher. São Paulo: Companhia das Letras, 2000.

LOURO, Guacira L. O corpo educado: pedagogias da sexualidade. Belo Horizonte: Autêntica, 2000.

. Um corpo estranho: ensaios sobre sexualidade e teoria queer. 2. ed. - Belo Horizonte: Autêntica, 2015.

MARQUEZINE, Bruna. “Carnaval: fui toda de @rosacha pro bloco da Favorita hoje!!!”. 10 fev. 2018. Post do Instagram. Disponível em: https://www.instagram.com/p/BfB0EUxli z/?hl=pt-br. Acesso em: 15 out. 2018.

PAIVA, Luciana L. Corpos amputados e protetizados: "naturalizando" novas formas de habitar o corpo na contemporaneidade. In: COUTO, Edvaldo S.; GOELLNER, Silvana V. (Org.). Corpos Mutantes: ensaios sobre novas (d)eficiências corporais. 2. ed. - Porto Alegre: Editora da UFRGS, 2009, p. 143-164.

SILVA, Fabiane F. da; RIBEIRO, Paula R. C. O governo dos corpos femininos entre as catadoras de lixo: (re)pensando algumas implicações da educação em saúde. Revista Estudos Feministas, Florianópolis, v. 16, n. 2, p. 557-580, maio-agosto/2008. ISSN 0104-026X. Disponível em: http://dx.doi.org/10.1590/S0104-026X2008000200013. Acesso em: 07 nov. 2018.

SANTOS, Luís Henrique Sacchi. Biopolíticas de HIV/AIDS no Brasil: uma análise dos anúncios televisivos das campanhas oficiais de prevenção (1986-2000). Porto Alegre: PPG em Educação FACED/UFRGS. Tese de Doutorado, 2002.

SOUZA, Márcia Rebeca R., et al. Droga de corpo! Imagens e representações do corpo feminino em revistas brasileiras. Revista Gaúcha de Enfermagem, Porto Alegre, v. 34, n. 2, p. 62-69, junho/2013. Disponível em: https://doi.org/10.1590/s1983-14472013000200008. Acesso em 12 jan. 2019. 
TUCHERMAN, Ieda. Corpo, fragmentos e ligações: a micro-história de alguns órgãos e de certas promessas. In: COUTO, Edvaldo S.; GOELLNER, Silvana V. (Org.). Corpos Mutantes: ensaios sobre novas (d)eficiências corporais. 2. ed. - Porto Alegre: Editora da UFRGS, 2009, p. 13-28. 